\title{
Energy Expenditure and Genotype of Children with Cystic Fibrosis
}

\author{
JEAN L. TOMEZSKO,' VIRGINIA A. STALLINGS, DEBORAH A. KAWCHAK, JAMES E. GOIN, \\ GILL DIAMOND, AND THOMAS F. SCANLIN \\ Divisions of Gastroenterology and Nutrition, and Genetics, The Cystic Fibrosis Center. The Children's Hospital \\ of Philadelphia, University of Pennsylvania School of Medicine, Philadelphia [J.L.T., V.A.S., D.A.K., G.D., T.F.S.J, \\ and Clinical Epidemiology Unit, University of Pennsylvania and General Clinical Research Center. \\ The Children's Hospital of Philadelphia, Philadelphia, Pennsylvania 19104 [J.E.G.]
}

\begin{abstract}
Increased energy expenditure, poor dietary intake, and fat malabsorption in patients with cystic fibrosis (CF) frequently lead to growth failure and malnutrition, which are associated with pulmonary failure and decreased survival. The study purpose was to understand better the energy expenditure and requirements in the mild pulmonary disease state in children. Resting and total energy expenditure were measured in 6- to 9-yr-old, pancreaticinsufficient children with $\mathrm{CF}(n=25)$ and control children $(n=25)$ of similar age, gender, and weight. The effect of the most common genotype, homozygous $\Delta \mathrm{F} 508$, on energy expenditure was also investigated. Dietary intake, degree of fat malabsorption, body composition, physical activity, and clinical status were determined. The CF group had a $9 \%$ increase in resting energy expenditure, which was not related to genotype or severity of lung disease. Both CF genotype subgroups ( $\triangle$ F508 homozygous and all others) had a similar, modest resting energy expenditure increase. Total energy expenditure was increased by $12 \%$ in the entire CF group and by $23 \%$ in the $\Delta F 508$ homozygous CF subgroup compared with controls. The total energy expenditure increase in $\Delta \mathrm{F} 508$ homozygous children may be related to increased voluntary physical activity, reflecting no activity reduction associated with lung disease, or to an unidentified genotype-related mechanism. The clinical implication is that a detailed physical activity assessment should be evaluated along with resting energy expenditure, either measured or estimated by equations, when daily energy needs are being determined for children with CF. (Pediatr Res 35: 451-460, 1994)
\end{abstract}

\section{Abbreviations}

CF, cystic fibrosis

REE, resting energy expenditure

TEE, total energy expenditure

FVC, forced vital capacity

$F E V_{1}$, forced expiratory volume in $1 \mathrm{~s}$

$\mathrm{FEF}_{25-75}$, forced expiratory flow between 0.25 and $0.75 \mathrm{~s}$

${ }^{2} \mathrm{H}$, deuterium

${ }^{18} \mathrm{O}$, oxygen-18

BW, body weight

Received July 28, 1993; accepted November 23, 1993.

Correspondence and reprint requests: Jean Tomezsko, Ph.D., R.D., Pediatric Pulmonary/Cystic Fibrosis Centers, Mail Stop 402, Hahnemann University Hospital, Broad and Vine Streets, Philadelphia, PA 19102.

Supported by the Cystic Fibrosis Foundation. Heinz Nutrition Center of The Children's Hospital of Philadelphia, and the National Institutes of Health Grant RR-00240 (General Clinic Research Center). Work performed in partial fulfillment of requirements for the degree of doctor of philosophy at the Pennsylvania State University (J.L.T.).

' Present address: Pediatric Pulmonary/Cystic Fibrosis Centers, Mail Stop 402, Hahnemann University Hospital, Broad and Vine Streets, Philadelphia, PA 19102.
FFM, fat-free mass

SF, skinfold

TBW, total body water

FQ, food quotient

$\mathbf{R Q}$, respiratory quotient

${ }^{2} \mathrm{H}_{2} \mathrm{O}$, deuterium oxide

$\mathrm{rCO}_{2}$, mean daily $\mathrm{CO}_{2}$ production

$\mathrm{CF}$, a common lethal genetic disorder with an autosomal recessive pattern of inheritance, is caused by mutations in the CF transmembrane conductance regulator gene (1-3). Generalized exocrine gland dysfunction results in abnormalities in several organ systems (4). In addition to the excessive losses of sodium chloride in sweat, abnormal mucus in the lungs contributes to the development of chronic obstruction, infection, and inflammation. Exocrine pancreatic insufficiency occurs in more than $85 \%$ of patients with CF, and, despite enzyme replacement therapy, malabsorption of fat and micronutrients may occur. According to a 1990 CF Foundation report, about $50 \%$ of patients cared for in the 114 organized CF centers had growth failure, with weight and/or height less than the 10th percentile for age and gender (5). CF-related growth failure is often attributed to chronic lung disease, although this causal relationship is not established.

Malnutrition may be caused by inadequate caloric intake, increased energy requirements, or both. The cause of the inadequate caloric intake is multifactorial, partly resulting from anorexia associated with lung infection and gastrointestinal discomfort associated with pancreatic insufficiency. Ingestion of multiple medications further interferes with appetite and food intake. Nutrient absorption, particularly fat, usually is decreased despite pancreatic enzyme supplementation. Energy expenditure may be increased as a result of chronic lung infection, fever, bronchodilator medications, a theorized increased work of breathing, and a possible basic molecular defect. The resulting negative energy balance depletes the body of its energy stores and impedes normal growth. Pencharz et al. (6) proposed that a vicious cycle is created in which the malnourished state places the child at risk for impoverished health because of lowered immune function, increased susceptibility to infections, continued anorexia, and inadequate food intake. The resulting catabolic state may be manifested by loss of skeletal mass, including respiratory muscles, and a decrease of lung elasticity, which further compromise the pulmonary system.

Energy expenditure in patients with $\mathrm{CF}$ has been previously investigated. Vaisman et al. (7) and Buchdahl $e t$ al. (8) documented an increase in REE in heterogeneous groups of patients with CF. TEE, using the doubly labeled water method, was 
reported by Shepherd et al. (9) to be increased in clinically well infants and toddlers with CF. In contrast, Spicher et al. (10), using a cumulative heart rate monitor method, found TEE to be equivalent between $\mathrm{CF}$ and healthy subjects despite increased $\mathrm{REE}$ in the CF group.

Contrasting findings exist regarding the pattern of energy expenditure among patients with the various genotypes of $\mathrm{CF}$. Fried $e t$ al. (11) found that in normally nourished men and boys with CF and good pulmonary function no association existed between REE and the $\triangle F 508$ homozygous genotype. Conversely, O'Rawe et al. (12) found that 7- to 15-yr-old subjects homozygous for $\Delta$ F508 had higher REE compared with $\Delta$ F508 heterozygous subjects or subjects with other mutations.

This study was designed to evaluate energy expenditure in a homogeneous prepubertal CF group who had pancreatic insufficiency, were well nourished with normal growth and body composition, and had mild pulmonary disease. This study avoids confounding variables such as poor lung function, malnutrition, and variable stages of pubertal development. The study hypotheses were as follows: 1) REE and TEE are higher in children with $\mathrm{CF}$ as compared with similar control children and 2) energy expenditure is related to CF genotype.

\section{MATERIALS AND METHODS}

Patients. Twenty-five prepubertal patients with CF were recruited from the CF center at The Children's Hospital of Philadelphia. Children were diagnosed with CF on the basis of clinical symptoms and duplicate quantitative pilocarpine iontophoresis sweat tests with sodium and chloride values greater than 60 $\mathrm{mEq} \cdot 1^{-1}$. All children were determined to be pancreatic insufficient on the basis of fecal fat analysis of a 72-h stool collection with $90 \%$ or less fat absorption, a stool trypsin value of less than $80 \mu \mathrm{m} \cdot \mathrm{g}^{-1}$, or both. Selection criteria for patients with CF were defined as follows: 1) 5 to 10 years of age, 2) no hospitalization 6 wk before the study, 3) no acute pulmonary exacerbation or other acute illness at the time of data collection, and 4) no other disease or prescribed medication known to affect growth. Study data were collected at the time of the routine annual comprehensive examination.

Twenty-five healthy children from hospital and community sources were recruited as control subjects. The enrollment of these children began after approximately one half of the $\mathrm{CF}$ group had been evaluated. The group of children with CF provided selection criteria for controls to ensure comparable age, gender, and weight. General selection criteria for control subjects were as follows: 1) 5 to 10 years of age, 2) a weight range of 16 to $34 \mathrm{~kg}, 3$ ) no known chronic or acute illness at the time of data collection, and 4) no other disease or prescribed medication known to affect growth. Individual matching of CF and control subjects was not carried out.

The study was conducted in the Nutrition and Growth Laboratory and the General Clinical Research Center of The Children's Hospital of Philadelphia during an 18-h overnight admission. Both parents and children gave informed written consent, and the protocol was approved by the Committee for the Protection of Human Subjects.

Growth and anthropometry. Weight, height, and SF thicknesses (triceps, biceps, subscapular, and suprailiac) were measured by one observer (J.T.) with standard methods as previously described $(13,14)$. Weight and height values were compared with National Center for Health Statistics reference standards (15), and percentiles and $z$ scores were determined (Centers for Disease Control Anthropometric Software Program, Version 3.1, 1988, Division of Nutrition, Centers for Disease Control, Atlanta, GA). Ideal BW was determined as the weight that corresponded to the weight for age percentile equal to the actual height for age percentile on the National Center for Health Statistics growth chart (16). Percentage body fat was calculated using the triceps and subscapular SF in the prepubertal prediction equations of
Slaughter et al. (17), which are adjusted for body density, body water, and bone density. FFM was determined using TBW values from ${ }^{2} \mathrm{H}_{2} \mathrm{O}$ dilution and assuming a $75.3 \%$ hydration factor of FFM in prepubertal children $(18,19)$.

Clinical status assessment. Clinical assessment of the patients with $\mathrm{CF}$ was based on consensus chest roentgenogram scores determined by two pediatric pulmonary physicians using the scoring system as described by Brasfield et al. (20). Clinical symptoms were rated by scores as described by Shwachman and Kulczycki (21). Pulmonary disease was evaluated at the time of the study in all patients with $\mathrm{CF}$ with standard pulmonary function methods for spirometry and plethysmography and compared with appropriate reference values $(22,23)$. These entities included FVC, $\mathrm{FEV}_{1}, \mathrm{FEF}_{25-75}$, and residual volume.

Three-day, weighed food records were collected at home as previously described (13). Food intake data were analyzed for 20 nutrients (Food Processor II Program-ESHA Research, Salem, OR). The home-based 72-h stool collection was begun on the 2 nd $d$ of the 3-d food record. Fecal fat was analyzed by the van de Kamer method (24) (Hahnemann University Hospital, Philadelphia, PA) or by a gravimetric method (Mayo Medical Laboratories, Rochester, MN). The coefficient of fat absorption was determined from fecal fat and dietary fat intake (25).

$R E E$. REE was measured by open-circuit indirect calorimetry. In preparation, each child was admitted the preceding afternoon and received an evening meal that was standardized for calories, carbohydrate, protein, and fat. Each child fasted from food and medication for 12-14 h before REE testing. In the early morning the child was awakened, an axillary temperature was recorded, and physical activity was restricted.

A computerized metabolic cart (Gould 2900 or SensorMedic 2900 Z, SensorMedics, Yorba Linda, CA) was used to measure REE for $60 \mathrm{~min}$ in a quiet, thermoneutral room. A large, clear ventilated hood for sampling gases was placed over the head of the subject while he or she was resting in a supine position. The modified equation as described by Weir (26) was used to calculate energy equivalency from the oxygen consumption and carbon dioxide production. The first 10 min were devoted to environmental adjustment by the child and were eliminated from calculations. REE data were compared with predicted values from World Health Organization basal metabolic rate equations (27).

$T E E$ and $T B W$. TEE was measured by the doubly labeled water method. The ${ }^{2} \mathrm{H}_{2} \mathrm{O}$ dose was $0.14 \mathrm{~g}{ }^{2} \mathrm{H}_{2} \mathrm{O} \cdot \mathrm{kg}$ estimated $\mathrm{TBW}^{-1}(28)$ and was 99.8 atom percent deuterium (Aldrich, Milwaukee, WI). The dose of ${ }^{18} \mathrm{O}$ in water was $0.3 \mathrm{~g} \mathrm{H}_{2}{ }^{18} \mathrm{O} \cdot \mathrm{kg}$ estimated $\mathrm{TBW}^{-1}(28)$ and ranged from 14 to $15 \%{ }^{18} \mathrm{O}$ (EG \& G Mound, Miamisburg, $\mathrm{OH}$ ).

On the day of admission, fasting began at $1830 \mathrm{~h}$, and a baseline urine sample was collected. At $2000 \mathrm{~h}$, the isotopes were administered orally. Overnight urine and the first urine void of the morning (1) were collected and pooled to adjust for isotope losses. The second urine void of $\mathrm{d} 1$ was collected to determine TBW $\left({ }^{2} \mathrm{H}_{2} \mathrm{O}\right)$ and to begin the TEE metabolic period. At home, the first urine voids of $\mathrm{d} 4,7$, and 10 were collected. The subjects observed their typical daily routines in their usual environment. Urinary ${ }^{2} \mathrm{H}$ and ${ }^{18} \mathrm{O}$ isotopic abundances were measured by isotope ratio mass spectroscopy (Nuclide 6-60, State College, PA; Global Geochemistry Corporation, Canoga Park, CA). Urinary ${ }^{2} \mathrm{H}$ samples were analyzed in duplicate, with reproducibility of \pm 5 parts per mille for isotopically enriched samples and \pm 3 parts per mille for the unenriched baseline samples. One out of $10{ }^{18} \mathrm{O}$ samples were analyzed in duplicate, and reproducibility was \pm 0.1 parts per mille.

Standard equations for calculation of TEE (18) were used, with adjustment for overnight loss after dosing: $\mathrm{rCO}_{2}=(\mathrm{N} /$ 2.078) $\left(1.01 \mathrm{k}_{\mathrm{o}}-1.04 \mathrm{k}_{\mathrm{H}}\right)-0.0246 \mathrm{r}_{\mathrm{G}}$, where $\mathrm{rCO}_{2}$ is mean daily $\mathrm{CO}_{2}$ production, $\mathrm{N}$ is TBW, $\mathrm{k}_{\mathrm{o}}$ and $\mathrm{k}_{\mathrm{H}}$ are ${ }^{18} \mathrm{O}$ and ${ }^{2} \mathrm{H}$ isotope elimination rates, and $\mathrm{r}_{\mathrm{Gr}}$ is the rate of water loss via fractionating gaseous routes. $\mathrm{r}_{\mathrm{Gf}}=1.05 \mathrm{~N}\left(1.01 \mathrm{k}_{\mathrm{o}}-1.04 \mathrm{k}_{\mathrm{H}}\right)$. The calculations assume that the ${ }^{2} \mathrm{H}$ and ${ }^{18} \mathrm{O}$ dilution spaces are 
Table 1. Growth and body composition characteristics of children with $C F$ and control children

\begin{tabular}{|c|c|c|c|c|c|c|}
\hline & \multicolumn{3}{|c|}{ Cystic fibrosis (13F/12M) } & \multicolumn{3}{|c|}{ Control $(11 \mathrm{~F} / 14 \mathrm{M})$} \\
\hline & Mean & SD & Range & Mean & SD & Range \\
\hline Age $(y)$ & 7.7 & 1.3 & $6.1-9.5$ & 7.6 & 1.1 & $5.7-10.1$ \\
\hline Weight (kg) & 23.9 & 4.4 & $16.5-34.0$ & 24.8 & 3.7 & $17.2-33.1$ \\
\hline Weight percentile & 39 & 25 & $3-93$ & 52 & 25 & $12-97$ \\
\hline Height (cm) & 123.2 & 8.3 & $109.9-139.4$ & 125.4 & 8.9 & $107.6-144.2$ \\
\hline Height percentile & 38 & 23 & $7-90$ & 54 & $26^{*}$ & $6-98$ \\
\hline \% Ideal BW & 101 & 8 & $86-117$ & 101 & 11 & $82-122$ \\
\hline Triceps SF (mm) & 9.0 & 2.3 & $4.8-15.9$ & 10.2 & 2.6 & $5.8-17.3$ \\
\hline Triceps $z$ score & -0.42 & 0.59 & $-1.32-1.19$ & 0.01 & $0.80^{*}$ & $-1.06-1.52$ \\
\hline$\%$ Body fat-SF & 13.6 & 3.3 & $5.5-22.7$ & 15.3 & 2.9 & $9.9-22.5$ \\
\hline$\%$ Body fat-TBW & 13.0 & 6.3 & $2.1-24.2$ & 17.4 & $5.2 \dagger$ & $8.7-30.2$ \\
\hline Upper arm circumference $(\mathrm{cm}) \ddagger$ & 18.9 & 1.9 & $14.9-22.4$ & 19.5 & 1.5 & $16.5-22.5$ \\
\hline Upper arm circumference $z$ score & -0.15 & 0.80 & $-1.55-1.36$ & 0.28 & 0.88 & $-1.21-1.77$ \\
\hline FFM (kg SF) & 20.6 & 3.6 & $15.6-29.9$ & 21.0 & 3.2 & $14.6-28.1$ \\
\hline FFM (kg TBW) & 20.7 & 3.6 & $14.8-29.7$ & 20.5 & 3.5 & $14.3-30.2$ \\
\hline
\end{tabular}

* Significant difference between groups by $t$ test, $p<0.05$.

† Significant difference between groups by $t$ test, $p<0.01$.

$\ddagger n=24$ for $\mathrm{CF}$ group.

Table 2. Energy expenditure and dietary intake of children with $C F$ and control children

\begin{tabular}{|c|c|c|c|c|c|c|c|c|}
\hline & \multicolumn{4}{|c|}{ Cystic fibrosis } & \multicolumn{4}{|c|}{ Control } \\
\hline & $n$ & Mean & SD & $95 \% \mathrm{CI}^{*}$ & $n$ & Mean & SD & $95 \% \mathrm{CI}^{*}$ \\
\hline $\begin{array}{l}\operatorname{REE}\left(\mathrm{kcal} \cdot \mathrm{d}^{-1}\right) \\
\operatorname{REE}\left(\% \mathrm{WHO}, \mathrm{kcal} \cdot \mathrm{d}^{-1}\right) \\
\operatorname{REE}\left(\mathrm{kcal}-\mathrm{kg} \mathrm{BW} \mathbf{H}^{-1} \cdot \mathrm{d}^{-1}\right) \\
\operatorname{REE}\left(\mathrm{kcal}-\mathrm{kg} \mathrm{FFM}-\mathrm{SF}^{-1} \cdot \mathrm{d}^{-1}\right) \\
\operatorname{REE}\left(\mathrm{kcal}-\mathrm{kg} \mathrm{FFM}-\mathrm{TBW}^{-1} \cdot \mathrm{d}^{-1}\right)\end{array}$ & $\begin{array}{l}23 \\
23 \\
23 \\
23 \\
23\end{array}$ & $\begin{array}{r}1193 \\
114 \\
50 \\
58 \\
58\end{array}$ & $\begin{array}{r}120 \\
7 \\
6 \\
6 \\
6\end{array}$ & $\begin{array}{c}1141-1245 \\
111-117 \\
47-53 \\
55-61 \\
55-61\end{array}$ & $\begin{array}{l}23 \\
23 \\
23 \\
23 \\
23\end{array}$ & $\begin{array}{r}1144 \\
108 \\
46 \\
55 \\
56\end{array}$ & $\begin{array}{c}111 \\
6 \dagger \\
4 \dagger \\
5 \ddagger \\
5\end{array}$ & $\begin{array}{c}1096-1192 \\
105-111 \\
44-48 \\
53-57 \\
54-58\end{array}$ \\
\hline $\begin{array}{l}\text { TEE }\left(\mathrm{kcal} \cdot \mathrm{d}^{-1}\right) \\
\text { TEE }\left(\% \mathrm{WHO}, \mathrm{kcal} \cdot \mathrm{d}^{-1}\right) \\
\text { TEE }\left(\mathrm{kcal}-\mathrm{kg} \mathrm{BW} \mathrm{BW}^{-1} \cdot \mathrm{d}^{-1}\right) \\
\text { TEE }\left(\% \mathrm{WHO}, \mathrm{kcal}-\mathrm{kg} \mathrm{BW}^{-1} \cdot \mathrm{d}^{-1}\right) \\
\text { TEE }\left(\mathrm{kcal}-\mathrm{kg} \mathrm{FFM}-\mathrm{SF}^{-1} \cdot \mathrm{d}^{-1}\right) \\
\text { TEE }\left(\mathrm{kcal}-\mathrm{kg} \mathrm{FFM}-\mathrm{TBW}^{-1} \cdot \mathrm{d}^{-1}\right) \\
\text { TEE/REE } \\
\text { TEE as \% dietary intake }\left(\mathrm{kcal} \cdot \mathrm{d}^{-1}\right)\end{array}$ & $\begin{array}{l}19 \\
19 \\
19 \\
19 \\
19 \\
19 \\
18 \\
19\end{array}$ & $\begin{array}{c}2012 \\
105 \\
84 \\
109 \\
97 \\
97 \\
1.68 \\
100\end{array}$ & $\begin{array}{l}435 \\
22 \\
17 \\
19 \\
19 \\
19 \\
0.31 \\
28\end{array}$ & $\begin{array}{c}1802-2222 \\
94-116 \\
76-92 \\
100-118 \\
88-106 \\
88-106 \\
1.53-1.83 \\
87-114\end{array}$ & $\begin{array}{l}23 \\
23 \\
23 \\
22 \\
23 \\
23 \\
22 \\
22\end{array}$ & $\begin{array}{c}1808 \\
96 \\
75 \\
95 \\
88 \\
88 \\
1.61 \\
103\end{array}$ & $\begin{array}{l}295 \\
12 \\
10 \\
12 \dagger \\
12 \\
12 \\
0.21 \\
18\end{array}$ & $\begin{array}{l}1680-1936 \\
91-101 \\
71-79 \\
90-100 \\
83-93 \\
83-93 \\
1.52-1.70 \\
95-111\end{array}$ \\
\hline $\begin{array}{l}\text { Intake }\left(\mathrm{kcal} \cdot \mathrm{d}^{-1}\right) \\
\text { Intake }\left(\mathrm{kcal} \cdot \mathbf{k g} \mathrm{BW} \cdot \mathrm{d}^{-1}\right) \\
\text { Intake }(\% 1989 \mathrm{RDA}) \\
\% \mathrm{kcal} \text { as fat }\end{array}$ & $\begin{array}{l}24 \\
24 \\
24 \\
24\end{array}$ & $\begin{array}{r}2060 \\
88 \\
103 \\
34\end{array}$ & $\begin{array}{r}447 \\
24 \\
22 \\
5\end{array}$ & $\begin{array}{c}1871-2249 \\
78-98 \\
94-112 \\
32-36\end{array}$ & $\begin{array}{l}24 \\
24 \\
24 \\
24\end{array}$ & $\begin{array}{r}1833 \\
75 \\
93 \\
32\end{array}$ & $\begin{array}{r}392 \\
16 \\
19 \\
6\end{array}$ & $\begin{array}{c}1167-1999 \\
68-82 \\
85-101 \\
29-35\end{array}$ \\
\hline
\end{tabular}

* CI, confidence interval.

$\dagger$ Significant difference between groups by $t$ test, $p \leq 0.05$.

$\ddagger$ Significant difference between groups by $t$ test, $p \leq 0.01$.

larger than the body water pool, $4 \%$ and $1 \%$ respectively (18), and that fractionated water loss is about $23 \%$ of total water turnover (29). The elimination rates for ${ }^{18} \mathrm{O}\left(\mathrm{k}_{\mathrm{o}}\right)$ and ${ }^{2} \mathrm{H}\left(\mathrm{k}_{\mathrm{H}}\right)$ were determined with the two-point method. The 9-d metabolic period was defined as the difference between $\mathrm{d} 1$ and $\mathrm{d} 10$. The d $7 \mathrm{rCO}_{2}$ was used as a consistency check of $\mathrm{d} 10 \mathrm{rCO}_{2}$. If $\mathrm{rCO}_{2}$ differed more than $10 \%$ between the $2 \mathrm{~d}$, data for that subject were excluded because of unacceptable variability. $R Q$ was estimated from the FQ (30), calculated from 3-d diet records during the metabolic period. In the patients with $\mathrm{CF}$, the $\mathrm{FQ}$ was adjusted for the coefficient of fat absorption. TEE data were compared with World Health Organization recommended energy requirements for children (27). Factors affecting the TEE metabolic period were recorded, i.e yearly season of metabolic period and prescribed use of bronchodilators that increase energy expenditure-heart rate. Documentation of actual bronchodilator compliance was not obtained.

Genotype analysis. Genomic DNA was isolated from blood samples (Applied Biosystems, Model 340A Nucleic Acid Extractor, Foster City, CA). The presence of the $\Delta \mathrm{F} 508$ mutation was determined by allele-specific oligonucleotide hybridization as described in Kerem et al. (3). Patients with CF were classified as $\Delta \mathrm{F} 508$ homozygous, $\triangle \mathrm{F} 508$ heterozygous, or having other mutations. Control subjects were not evaluated.

Estimates of physical activity. Parents estimated their child's physical activity each day during the metabolic period. A questionnaire adapted from Murphy et al. (31) provided a score for daily physical activity: sedentary $=1$, slightly active $=2$, moderately active $=3$, and active $=4$. Parents chose the category that best described the child's physical activity for each day, and the mode score for the 9-d metabolic period was used to classify the overall activity. The TEE/REE ratio, representing the energy used for physical activity, thermic effect of food, and growth, was also calculated.

Statistical analysis. Univariate comparisons of growth, body composition, dietary intake, and energy expenditure between the two groups of children were evaluated by examining means, SD, $95 \%$ confidence intervals, and range of values within each group. Unpaired $t$ tests, with logarithm transforms when appropriate, were used to measure distribution differences between the two groups and to assess statistical significance. Additional univariate comparisons were performed by separating the children with CF 
A)

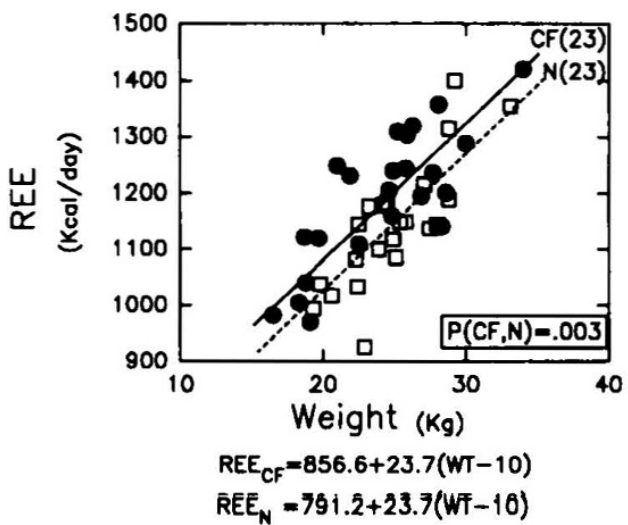

B)

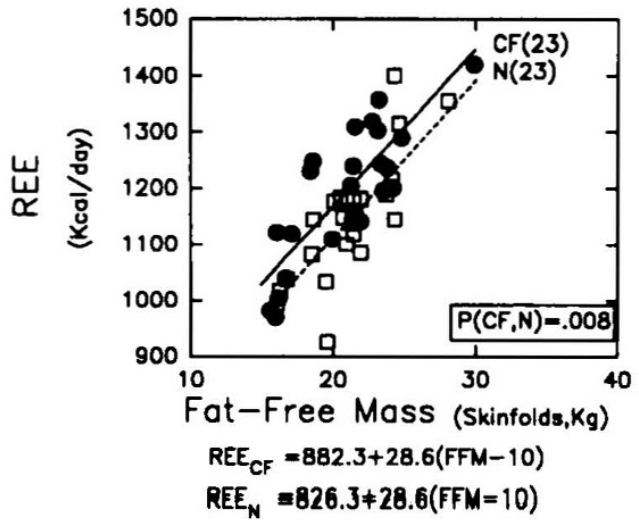

C)

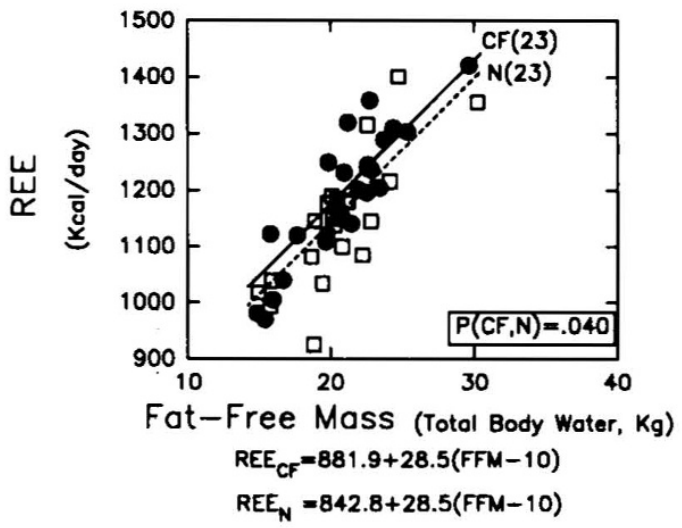

KEY: - CF, a N, Sample Size (N)

Fig. 1. Analysis of covariance of REE and BW $(A)$, FFM from two SF measurements $(B)$, and FFM from TBW $(C)$ in children with CF $(C F)$ and control children $(N)$.

into two subgroups: homozygous $\Delta \mathrm{F} 508$ and all other genotypes. Univariate comparisons for ordinal scaled variables were accomplished with the Wilcoxon rank sum statistic, and categorical variables were determined by corrected $\chi^{2}$ and Fisher's exact tests. All data analysis was performed with SAS (SAS Institute, Cary, NC), with a conservative two-tailed testing approach.

The primary analysis for energy expenditure differences of groups and subgroups was based on linear model adjustment using covariates known or suspected to influence energy expenditure. This analysis of covariance method accommodated adjustment for weight, gender, body composition measures of FFM, and genotype. It also allowed the interaction of these covariates to be evaluated and the validity of the model(s) to be assessed. A small bias may appear in these estimates with FFM adjustment because of the inherent variability associated with its estimation. Outliers in these models were identified by evaluating studentized residuals for each model. Sensitivity analyses were performed by deleting outlier observations, applying logarithm transforms, and estimating missing values by the method of Bartlett (32). Pulmonary function differences between the two subgroups of children with CF were evaluated with the linear model with adjustment for age, gender, and weight.

\section{RESULTS}

Growth and clinical characteristics. Growth and body composition characteristics for all subjects are presented in Table 1. Age, weight, and height were similar for the CF and control groups, which reflects the procedure used for selecting controls. However, mean height for age percentile was lower for the CF group. Nutritional status, as indicated by percentage ideal BW, was similar for both groups. Most body composition measures were comparable, with the exceptions of triceps $z$ score and percentage body fat determined by TBW, both of which were lower for the CF group. Mean \pm SD (range) of pulmonary function, indicated by $\mathrm{FEV}_{1}$ percentage predicted, was $89 \pm 16 \%$ (61-117\%), and the chest roentgenogram score was $21 \pm 2$ (1624), out of a maximum score of 25 . These measures indicated mild pulmonary disease for the children with CF. The CF clinical severity score was $89 \pm 5(78-97)$, which reflects excellent clinical status.

$R E E$. The REE results of four subjects (two with CF and two control) were omitted because of equipment malfunction. REE values (Table 2) demonstrated higher means in children with $\mathrm{CF}$, e.g. an $8.5 \%$ difference between mean values for $\mathrm{kcal} \cdot \mathrm{kg} \cdot \mathrm{d}$ 
Table 3. Energy expenditure and dietary intake of children with $C F$, by genotype, and control children

\begin{tabular}{|c|c|c|c|c|c|c|c|c|c|c|c|c|}
\hline & \multicolumn{4}{|c|}{$\Delta \mathrm{F} 508 / \Delta \mathrm{F} 508^{*}$} & \multicolumn{4}{|c|}{$\Delta \mathrm{F} 508 / \mathrm{O}$ and $\mathrm{O} / \mathrm{O}^{*}$} & \multicolumn{4}{|c|}{ Control } \\
\hline Age (y) & 14 & 7.7 & 1.4 & $6.1-9.5$ & 11 & 7.8 & 1.3 & $6.1-9.4$ & 25 & 7.6 & 1.1 & $5.7-10.1$ \\
\hline Weight percentile & 14 & 41 & 25 & $12-93$ & 11 & 37 & 27 & $3-89$ & 25 & 52 & 25 & $12-97$ \\
\hline Height percentile & 14 & 39 & 24 & $11-90$ & 11 & 37 & 23 & $7-71$ & 25 & 54 & 26 & $6-98$ \\
\hline \% Ideal BW & 14 & 100 & 9 & $86-117$ & 11 & 102 & 7 & $88-112$ & 25 & 101 & 11 & $82-122$ \\
\hline \multirow[t]{2}{*}{$\mathrm{FEV}_{1}$ (\% predicted) } & 12 & 93 & 14 & $67-114$ & 11 & 85 & 19 & $61-117$ & & & & \\
\hline & $n$ & Mean & SD & $\mathrm{CI} \dagger$ & $n$ & Mean & SD & $\mathrm{Cl} \dagger$ & $n$ & Mean & SD & $\mathrm{CI}+$ \\
\hline $\operatorname{REE}\left(\mathrm{kcal} \cdot \mathrm{d}^{-1}\right)$ & 13 & 1191 & 99 & $1131-1251$ & 10 & 1197 & 148 & $1091-1303$ & 23 & 1144 & 111 & $1096-1192$ \\
\hline REE (\% WHO, $\left.\mathrm{kcal} \cdot \mathrm{d}^{-1}\right)$ & 13 & 114 & 7 & $110-118$ & 10 & 115 & 7 & $110-120$ & 23 & 108 & 6 & $105-111$ \\
\hline $\operatorname{REE}\left(\mathrm{kcal} \cdot \mathrm{kg} \mathrm{BW}{ }^{-1} \cdot \mathrm{d}^{-1}\right)$ & 13 & 50 & 6 & $46-54$ & 10 & 50 & 6 & $46-54$ & 23 & 46 & 4 & $44-48$ \\
\hline TEE/REE ratio & 10 & 1.85 & 0.26 & $1.66-2.04$ & 8 & 1.46 & 0.21 & $1.28-1.64$ & 22 & 1.61 & 0.21 & $1.52-1.7$ \\
\hline Intake $\left(\mathrm{kcal} \cdot \mathrm{d}^{-1}\right)$ & 14 & 1983 & 46 & $1714-2252$ & 10 & 2168 & 419 & $1868-2468$ & 24 & 1833 & 392 & $1167-1999$ \\
\hline Intake $\left(\mathrm{kcal} \cdot \mathrm{kg} \mathrm{BW} \cdot \mathrm{d}^{-1}\right)$ & 14 & 84 & 19 & $73-95$ & 10 & 93 & 29 & $72-114$ & 24 & 75 & 16 & $68-82$ \\
\hline Intake (\% 1989 RDA) & 14 & 100 & 23 & $87-113$ & 10 & 108 & 21 & $93-123$ & 24 & 93 & 19 & $85-101$ \\
\hline$\% \mathrm{kcal}$ as fat & 14 & 32 & 5 & $29-35$ & 10 & 36 & 5 & $32-40$ & 24 & 32 & 6 & $29-35$ \\
\hline
\end{tabular}

* $\Delta \mathrm{F} 508 / \Delta \mathrm{F} 508$ homozygous genotype; $\triangle \mathrm{F} 508 / \mathrm{O}$ heterozygous and unknown mutation; $\mathrm{O} / \mathrm{O}$ unknown mutation.

$+\mathrm{CI}$, confidence interval.

and $3.6 \%$ difference for $\mathrm{kcal} \cdot \mathrm{kg} \cdot \mathrm{FFM} \cdot \mathrm{d}^{-1}$ by TBW (FFMTBW).

Differences in REE between groups were evaluated adjusting for weight, FFM, and gender, all of which are factors known to influence REE. Using weight, FFM-SF, or FFM-TBW as covariates in three separate models (Fig. $1 A-C$ ) yielded greater $\mathrm{CF}$ group differences, compared with controls, of $65.4 \mathrm{kcal} \cdot \mathrm{d}^{-1}$ for weight $(p=0.003), 56.0 \mathrm{kcal} \cdot \mathrm{d}^{-1}$ for FFM-SF $(p=0.008)$, and $39.1 \mathrm{kcal} \cdot \mathrm{d}^{-1}$ for FFM-TBW $(p=0.04)$. Including gender (not shown) in the model with weight provided an adjusted group difference of $70.9 \mathrm{kcal} \cdot \mathrm{d}^{-1}(p=0.001)$, with boys having higher REE in both groups.

Controlling for gender and FFM-SF provided an adjusted group difference of $60.6 \mathrm{kcal} \cdot \mathrm{d}^{-1}(p=0.003)$. Gender was not an important factor for adjustment with FFM-TBW $(p=0.14)$. The influence of two control subject outliers (Fig. 1 $A$ ) was investigated and did not alter results. In fact, analysis excluding the two outliers resulted in more significant $p$ values for differences between groups, e.g. $p=0.02$ with FFM-TBW (Fig. 1C).

Genotype classifications (Table 3 ) had $14(56 \%)$ patients who were homozygous for the $\Delta \mathrm{F} 508$ mutation, $7(28 \%)$ heterozygous $(\Delta F 508 /$ unknown), and $4(16 \%)$ unknown mutations. These latter 11 patients were grouped together as the mixed heterozygous subgroup and compared with the 14 homozygous patients. Adjusting for weight and FFM separately yielded similar REE results for the two CF subgroups (Fig. $2 A-C$ ). The REE for both CF subgroups was significantly higher than the control group when the model was adjusted for either weight or FFM-SF. When FFM-TBW was used to adjust the model, the homozygous subgroup was not different from controls $(p=0.18)$. Estimated mean REE differences between the two CF subgroups were 5.2 $\mathrm{kcal} \cdot \mathrm{d}^{-1}$ for weight adjustment, $7.0 \mathrm{kcal} \cdot \mathrm{d}^{-1}$ for FFM-SF adjustment, and $20.9 \mathrm{kcal} \cdot \mathrm{d}^{-1}$ for FFM-TBW adjustment. Including gender in the model with weight or with FFM-SF provided similar results. However, the model with gender and FFM-TBW (not shown) indicated no significant difference between the homozygous subgroup and controls despite a significant differ- ence ( $p=0.04$ ) between the mixed heterozygous subgroup and controls.

$T E E$. The TEE results of eight subjects (six with CF and two control) were excluded because of unacceptably high variability in $\mathrm{rCO}_{2}$. The $\mathrm{CF}$ group (Table 2) had $12 \%$ higher TEE expressed as $\mathrm{kcal} \cdot \mathrm{kg}$ body weight ${ }^{-1} \cdot \mathrm{d}^{-1}$ compared with the control group, with $95 \%$ confidence intervals of 76 to 92 and 71 to 79 , respectively. Mean differences between the TEE of CF and control groups were $9-12 \%$ less in the control group when TEE were expressed in other units.

Analysis of TEE as measured by $\mathrm{kcal} \cdot \mathrm{d}^{-1}$ yielded a significant difference of $216 \mathrm{kcal} \cdot \mathrm{d}^{-1}(p=0.04)$ between the CF and control groups when adjusted for weight (Fig. $3 A$ ). TEE analysis, adjusted for weight and gender (Fig. $3 B$ ) showed that boys had higher TEE, $234 \mathrm{kcal} \cdot \mathrm{d}^{-1}$, in both CF and control groups. When FFMSF or FFM-TBW were used for adjustment (Fig. $3 C$ and $D$ ), differences between the CF and control groups were smaller (191 $\mathrm{kcal} \cdot \mathrm{d}^{1}$ for FFM-SF and $156 \mathrm{kcal} \cdot \mathrm{d}^{-1}$ for FFM-TBW). Four outlier observations, three CF and one control, were identified (Fig. 3A). Deleting these observations resulted in higher $p$ values: $p=0.11$ (weight), $p=0.17$ (FFM-SF), and $p=0.16$ (FFM-TBW).

In marked contrast to the REE genotype analysis, the $\triangle F 508$ homozygous children expended $21 \%$ and $23 \%$ more total daily energy $\left(\mathrm{kcal} \cdot \mathrm{kg} \cdot \mathrm{d}^{-1}\right)$ than the mixed heterozygous subgroup and the controls, respectively. TEE, adjusted for weight, resulted in a difference of $406 \mathrm{kcal} \cdot \mathrm{d}^{-1}(p=0.004)$ between the $\Delta \mathrm{F} 508$ homozygous subgroup versus the mixed heterozygous subgroup and a difference of $408 \mathrm{kcal} \cdot \mathrm{d}^{-1}(p=0.001)$ between the homozygous $\Delta$ F508 subgroup versus the control group (Fig. 2D). In this model, a difference of only $2.7 \mathrm{kcal} \cdot \mathrm{d}^{-1}$ was observed between the mixed heterozygous subgroup and the control group. Removing the four outliers yielded smaller differences between the homozygous subgroup and mixed heterozygous $(p=0.06)$ and control $(p=0.02)$ subjects.

Food intake, lung function, and physical activity. For children with CF, caloric intake was $17 \%$ higher $(p=0.04)$ when $\mathrm{kcal}$. $\mathrm{kg} \cdot \mathrm{d}^{-1}$ were examined. Dietary intake was about $100 \%$ of TEE 
A)

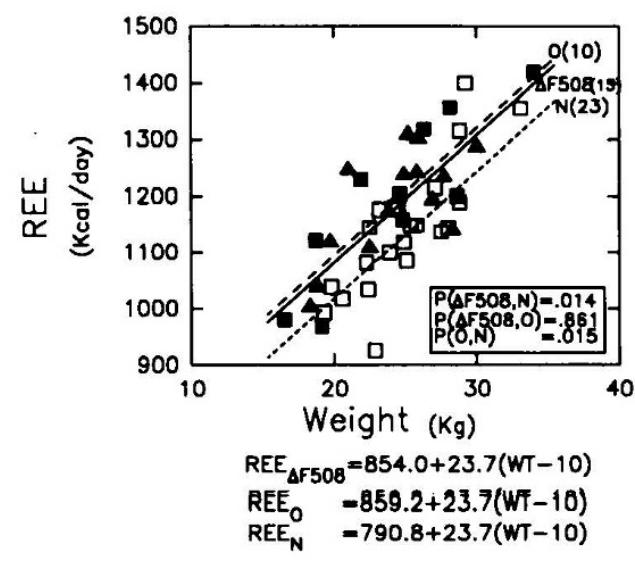

C)

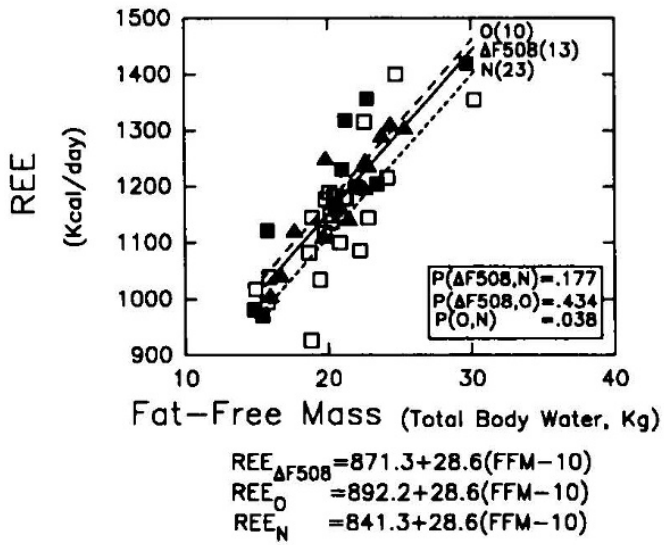

B)

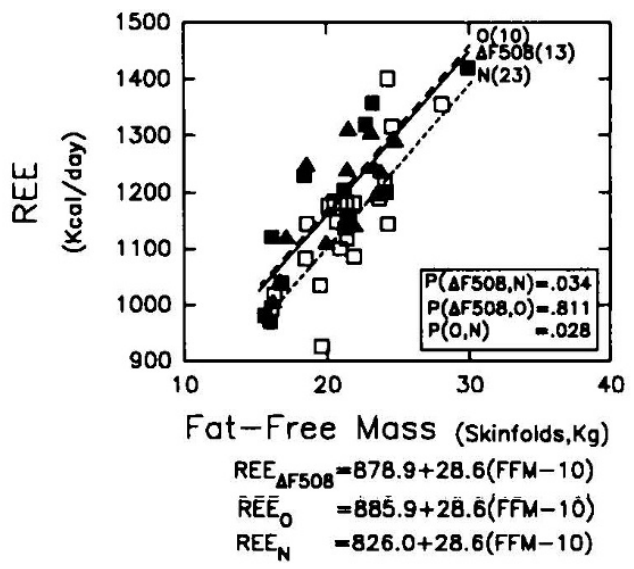

D)

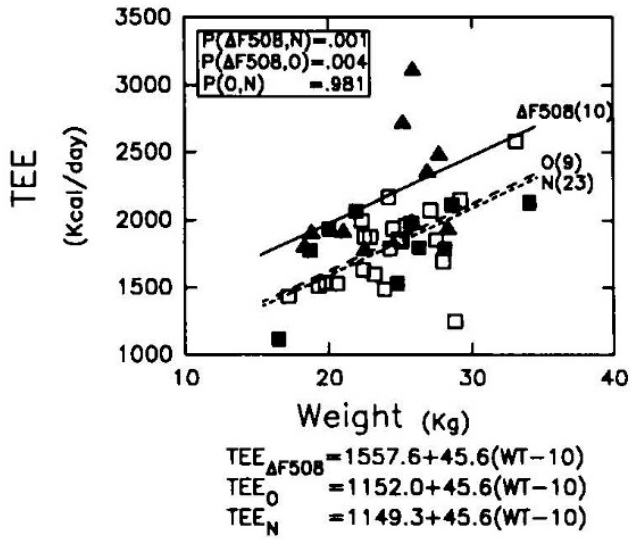

$$
\begin{aligned}
& \text { KEY: }=C F \Delta F 508 / \Delta F 508, \quad-\text { =Other } C F, \quad \square=\text { Normal } \\
& \text { Sample Size }(N)
\end{aligned}
$$

Fig. 2. Analysis of covariance of REE by weight and FFM presented by genotype category in children with CF and controls ( $A-C)$ and of TEE by weight presented by genotype category in children with $\mathrm{CF}(C F)$ and controls $(N)(D)$.

in both groups. Small differences were found between the two genotype subgroups and the control group in caloric intake (Table 3). The mean coefficient of fat absorption from the stool analysis for 23 of the patients with CF was $87 \%$, and the median value was $90 \%$. FQ, calculated from TEE metabolic period diet records, was used to determine RQ for the calculation of TEE. RQ for patients with CF was adjusted for loss of stool fat with the coefficient of fat absorption. The mean RQ for the CF group was 0.88 before and after stool fat adjustment, and the unadjusted $F Q$, also 0.88 , was used as the $R Q$ for the control group.

The effect of lung disease on REE and TEE, as measured by FEV , and FVC\% predicted, resulted in no significant associations. When genotype subgroup data were compared, including age, gender, and weight (either singly or combined) in the linear model, similar results were found. Patients with CF were examined for the effect of genotype ( $\triangle \mathrm{F} 508$ homozygous subgroup versus mixed heterozygotes) on pulmonary function. Nonsignificant differences (mean \pm SD) were observed: FVC, $105 \pm 12 \%$ versus $99 \pm 12 \%$ predicted; $\mathrm{FEV}_{1}, 93 \pm 14 \%$ versus $85 \pm 19 \%$ predicted; $\mathrm{FEV}_{1} / \mathrm{FVC}, 90 \pm 10 \%$ versus $85 \pm 16 \%$ predicted; $\mathrm{FEF}_{25-75}, 75 \pm 24 \%$ versus $72 \pm 38 \%$ predicted; and residual volume, $144 \pm 54 \%$ versus $178 \pm 48 \%$ predicted. The $\Delta \mathrm{F} 508$ homozygous subgroup tended to have better scores for these pulmonary measures.

TEE divided by REE is an indicator of physical activity and thermic effect of food during the 9-d metabolic period. Thermic effect of food was not measured and was assumed to be similar in all groups and subgroups. The TEE/REE ratios (Table 2) were not statistically different between the entire $\mathrm{CF}$ and control groups, adjusting for weight or FFM. However, a difference in the ratio was noted between the $\Delta \mathrm{F} 508$ homozygous and the mixed heterozygous subgroups (Table 3 ). The control group ratio, which was located between those of the two CF subgroups, was different from both. Physical activity scores from parental observations for the two genotype CF subgroups and the control group were compared with rank test procedures, and no differences were observed.

\section{DISCUSSION}

There were several salient findings in this study of adequately nourished, prepubertal, pancreatic-insufficient children with mild lung manifestations of CF. First, REE was increased 6-9\% above controls and appeared independent of genotype subgroup 
A)

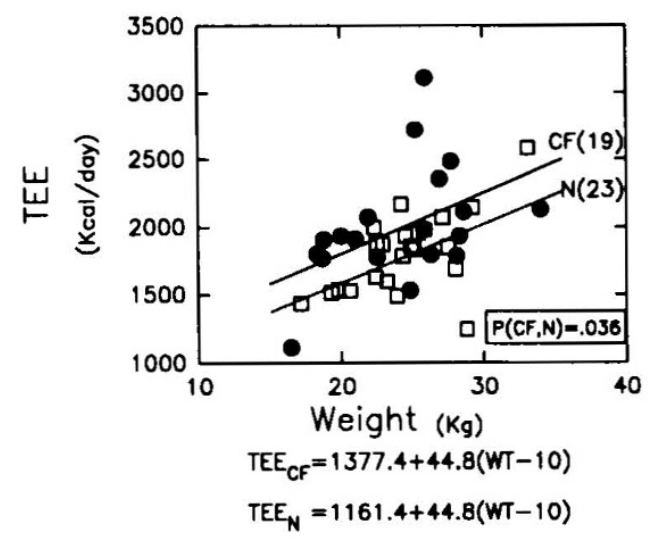

C)

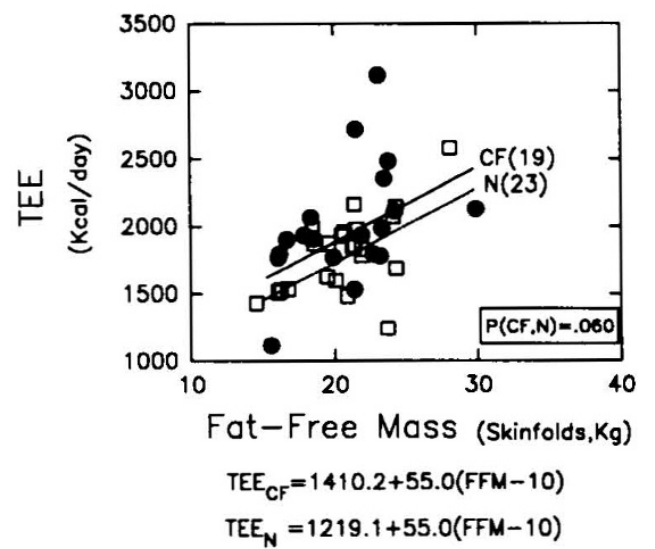

B)

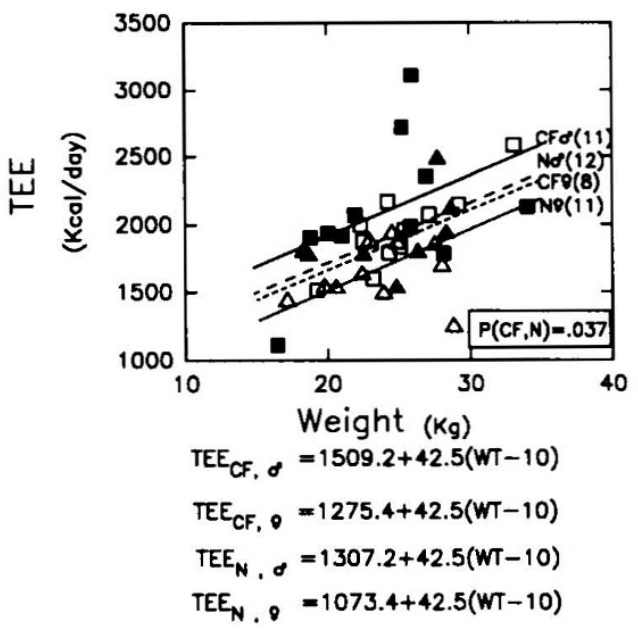

D)

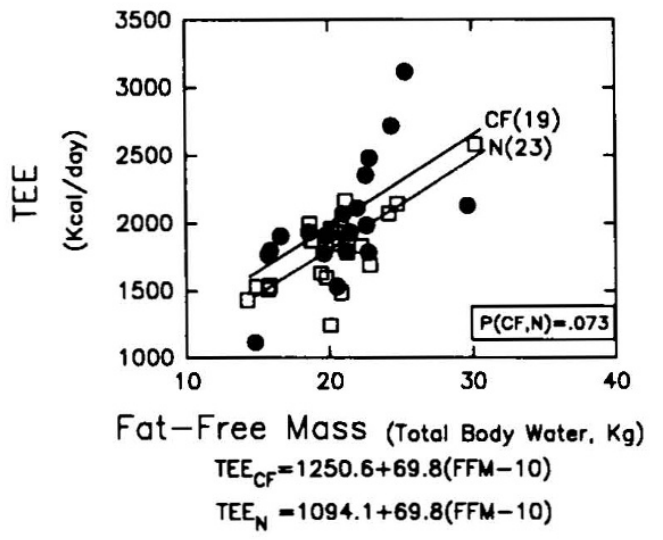

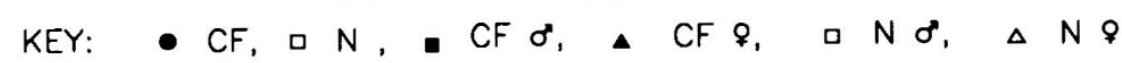
Sample Size $(N)$

Fig. 3. Analysis of covariance of TEE by weight $(A)$, weight and gender $(B)$, FFM from two SF measurements $(C)$, and FFM $(D)$ from TBW in children with $\mathrm{CF}(C F)$ and control children $(N)$.

( $\triangle \mathrm{F} 508$ homozygous compared with all others) or of mild pulmonary dysfunction. Second, TEE was about $15-18 \%$ greater in children with CF compared with controls. The statistical significance of this increase was documented by sensitivity analysis methods, including estimation of missing TEE values. Third, the increase in CF TEE was attributed principally to the $\Delta \mathrm{F} 508$ homozygous subgroup and was not explained by pulmonary function, the season during which TEE was measured, or use of bronchodilator medications. Vaisman et al. (33) found that REE was increased by use of salbutamol in patients with CF. Physical activity, as reflected by the TEE/REE ratio, was increased in the $\Delta F 508$ homozygous subgroup. It appears that in this $C F$ subgroup with mild lung disease no compensation by decreased physical activity occurred, as described by Spicher et al. (10). However, the subjective activity score from parental observations showed no difference in physical activity between the CF and control groups or between the two CF subgroups and controls. It is generally noteworthy that statistical control for influential covariates is critical for detecting small differences between groups; however, caution is still required in interpreting the results from these models.

The CF REE values reported here are similar to those of
Buchdahl et al. (8), which were 7-9\% above predicted using a regression equation generated from a comparable control group (Table 4). Their patients with CF were children and adolescents with highly variable lung function. Vaisman et al. (7) found REE in patients with CF to be $18 \%$ above predicted using the HarrisBenedict equations (34); however, these equations are inappropriate for prediction in their younger subjects. Furthermore, Vaisman's patients with CF varied with respect to age and lung disease. Fried et al. (11) described a curvilinear relationship with increasing REE and decreasing pulmonary function in male patients with $\mathrm{CF}$ and variable lung disease.

Our patients with $C F$ represent a restricted range of mild to moderate lung disease where pulmonary function was not a major contributing factor to REE. The 6-9\% increase in REE may be related to a number of factors, including an energyrequiring cellular defect; energy expenditure related to unmeasured, mild chronic pulmonary inflammation and infection; and an increase in work related to pulmonary disease not detected by these pulmonary function tests.

REE and genotype association was examined by Fried $e t$ al. (11), who found no relationship, and by O'Rawe et al. (12), who described an increased REE in the $\Delta$ F508 homozygous subgroup. 


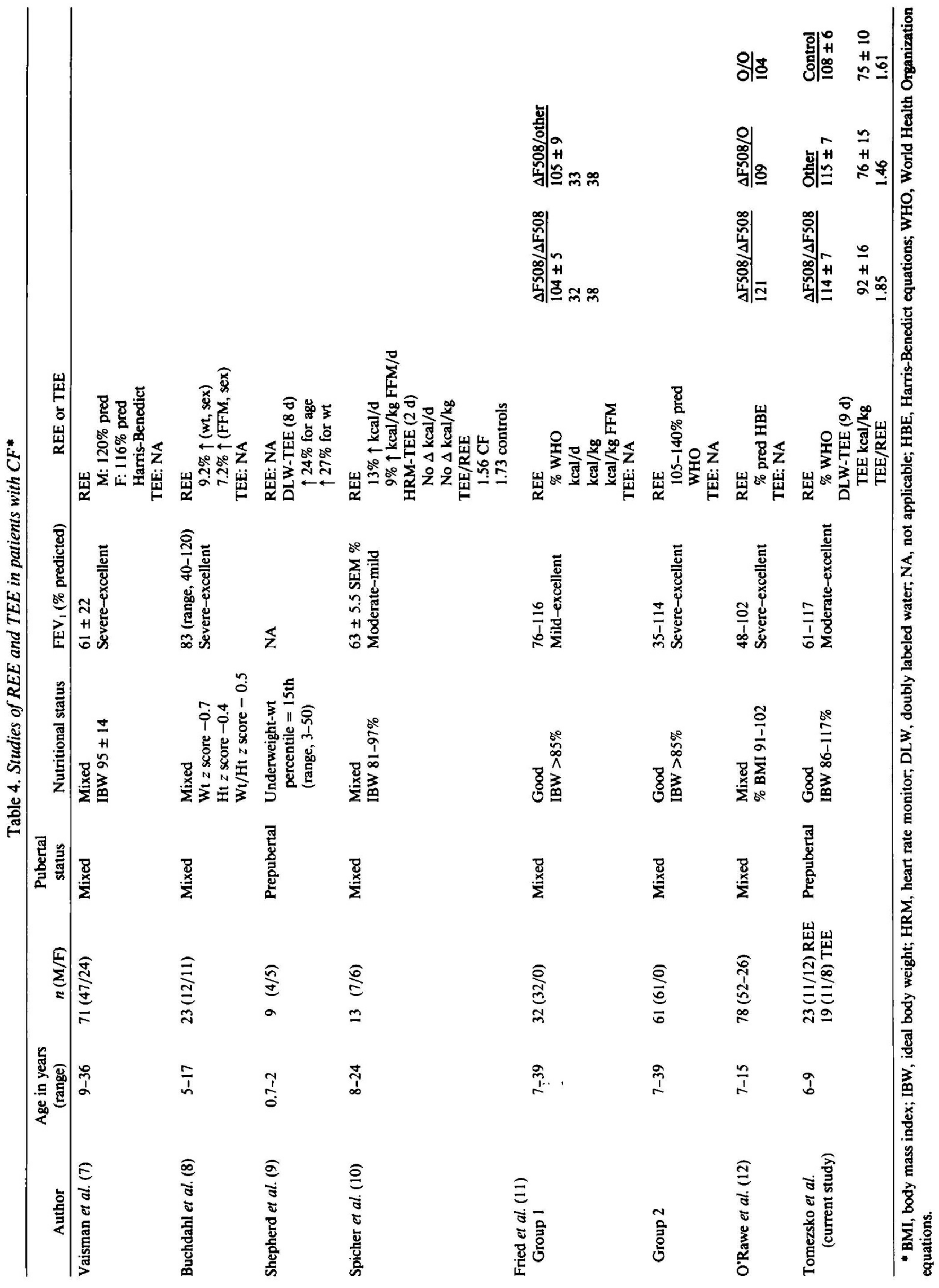


The latter results may be an artifact because of the use of the Harris-Benedict equations for nonadult subjects or because of the effect of severe lung disease and malnutrition in their CF group.

The TEE results reported here are similar to those of Shepherd et al. (9), who found a $27 \%$ increase in TEE in clinically well infants and children with CF using the doubly labeled water method. Discussion of the interpretation of these data has centered mainly on the adequacy of the control group (35-38). Spicher $e t$ al. (10), using the 48-h heart rate monitor method for TEE, found no difference between CF and control groups despite higher REE for patients with CF. This lack of difference was attributed to reduced voluntary physical activity, i.e. compensation in the patients with $\mathrm{CF}$.

The exclusion of eight TEE values as a result of unacceptably high variability in $\mathrm{rCO}_{2}$ was probably due to contaminated samples or inaccurate analysis, not to disparate subject characteristics. One explanation for our $23 \%$ higher TEE in the $\triangle \mathrm{F} 508$ homozygous subgroup is that voluntary physical activity was higher during the metabolic period. The four outlier patients may have exhibited extremes of activity, either typical or not, in their normal environment. Compensation by decreased physical activity as suggested by Spicher et al. (10) was not observed. TEE/REE ratios, which are influenced mainly by physical activity, support this explanation, although the activity scores from parental observations do not. The $\Delta \mathrm{F} 508$ homozygous subgroup ratio (1.85) was close to reference values for normal children (1.8 to 1.9) (39); however, the ratios of the other subgroups were lower. In comparison, the TEE/REE ratios reported by Spicher et al. (10) were 1.56 for $\mathrm{CF}$ and 1.73 for control subjects. Another explanation for higher TEE is that all three groups had similar levels of physical activity but that the energy cost of physical activity was greater in the homozygous subgroup. Grunow et al. (40) reported that energy expenditure was significantly increased during activities of daily living in normally nourished female patients with CF and that this incremental increase in energy from the resting state to each activity level was comparable in $\mathrm{CF}$ and control groups. Their study did not assess subjects by genotype. Future studies of TEE, combined with more direct measures of physical activity, are needed.

Isotopic fractionation is an important issue in the clinical use of the doubly labeled water method and refers to the lower rate of vaporization of heavier isotopes compared with the lighter isotopes of the same element. It is assumed that breath water vapor and insensible transcutaneous water are fractionated and that sweat and urine are not (18). We assumed that isotopic fractionation was the same for patients with CF and control subjects. CF results in abnormal amounts of sodium and chloride in the sweat without affecting the insensible water losses from the cutaneous layer. $\mathrm{CO}_{2}$ concentration was assumed to be $3.5 \%$ of expired air for the fractionation calculations. To verify this, we measured $\mathrm{CO}_{2}$ concentration in four patients with $\mathrm{CF}$ (mean $\pm \mathrm{SD}, 2.5 \pm 0.5 \%$ ) and five control subjects (mean $\pm \mathrm{SD}, 3.1 \pm$ $0.8 \%$ ) in this study. Assuming a $\mathrm{CO}_{2}$ value of $2.5 \%$ resulted in a $1.8 \%$ lower $\mathrm{rCO}_{2}$ and $2.6 \%$ higher $\mathrm{rCO}_{2}$ for maximal and minimal breath water loss, respectively. Because of these small $\mathrm{rCO}_{2}$ differences, the original assumption of Schoeller et al. (18) (3.5\% $\mathrm{CO}_{2}$ and saturated breath water vapor) were used.

Clinical significance. Children with $\mathrm{CF}$ who were selected because of their mild lung disease, good nutritional status, and normal growth had a modest (6-9\%) increase in REE. This increase could not be explained by genotype or degree of lung disease. TEE from normal daily activity was also increased in children with $\mathrm{CF}$, but the increase of $15 \%$ was greater than the $6-9 \%$ accounted for by REE alone. When TEE was examined by genotype, the $\Delta \mathrm{F} 508$ homozygous subgroup demonstrated a $22 \%$ greater increase compared with that of the control children. Unexpectedly, children with non- $\Delta$ F508 homozygous mutations had equivalent TEE to controls. Because of the mixed heterogeneous nature of this subgroup, definite conclusions could not be drawn about its relationship to the $\Delta \mathrm{F} 508$ homozygous subgroup or controls.

The increase in TEE in homozygous children may be related to increased voluntary physical activity as indicated by the TEE/ REE ratio, although the parental activity score did not support this. Other causes include the possibility that the $\Delta \mathrm{F} 508$ homozygous mutation caused a cellular or adaptive response resulting in an increased energy requirement for a given amount of physical activity. The clinical implication of this pattern of energy expenditure is that REE, either measured or estimated from equations, may not reflect the variability of physical activity and therefore may poorly predict the total daily energy needs of children with CF. Detailed assessment of current physical activity level for each individual with CF may be necessary to determine an accurate caloric goal for optimal growth or nutritional rehabilitation.

This information may provide a basis for the interpretation of previous studies (Table 4), explaining some of the conflicting findings expressed among studies because of varying subject populations. Recognition of the relationship between genotype and REE and TEE will aid our understanding of growth failure, malnutrition, and progression of pulmonary disease in children with $\mathrm{CF}$.

Acknowledgments. The authors thank the children and their families and Sharon Sasanow, Betty Leifer, Dr. Edward Tomezsko, Damary Vargas, Monica Darby, Joseph McDonough, Dr. Michael Bennett, Dr. Elsworth Buskirk, Dr. Penny Kris-Etherton, Dr. Dale Schoeller, and the General Clinical Research Center staff.

\section{REFERENCES}

1. Rommens J, Iannuzzi M, Kerem B, Drumm M. Melmer G, Dean M, Rozmahel R, Cole J, Kennedy D. Hidaka N, Zsiga M, Buchwald M, Riordan J, Tsui L, Collins F 1989 Identification of the cystic fibrosis gene: chromosome walking and jumping. Science 245:1059-1065

2. Riordan J, Rommens J, Kerem B, Alon N, Rozmahel R, Grzelczak Z, Zielenski J, Lok S. Plavsic N, Chou J, Drumm M, lannuzzi M, Collins F, Tsui L 1989 Identification of the cystic fibrosis gene: cloning and characterization of complementary DNA. Science 245:1066-1072

3. Kerem B, Rommens J, Buchanan J, Markiewicz D, Cox T, Chakravarti A, Buchwald M, Tsui L 1989 Identification of the cystic fibrosis gene: genetic analysis. Science 245:1073-1080

4. Scanlin T 1988 Cystic fibrosis. In: Fishman A (ed) Pulmonary Disease and Disorders. McGraw-Hill, New York, pp 1973-1993

5. FitzSimmons S 1993 The changing epidemiology of cystic fibrosis. J Pediatr 122:1-9

6. Pencharz P. Hill R, Archibald E, Levy L, Newth C 1984 Energy needs and nutritional rehabilitation in undernourished adolescents and young adult patients with cystic fibrosis. J Pediatr Gastroenterol Nutr 3(suppl1):S147S153

7. Vaisman N, Pencharz P, Corey M, Canny G, Hahn E 1987 Energy expenditure of patients with cystic fibrosis. J Pediatr 111:496-500

8. Buchdahl R, Cox M, Fulleylove C, Marchant J, Tomkins A, Brueton M, Warner J 1988 Increased resting energy expenditure in cystic fibrosis. J Appl Physiol 64:1810-1816

9. Shepherd R, Vasques-Velasquez L, Prentice A, Holt T, Coward W, Lucas A 1988 Increased energy expenditure in young children with cystic fibrosis. Lancet 1:1300-1303

10. Spicher V, Roulet M, Schutz Y 1991 Assessment of total energy expenditure in free-living patients with cystic fibrosis. J Pediatr 118:865-872

11. Fried M, Durie P, Tsui L, Corey M, Levison H, Pencharz P 1991 The cystic fibrosis gene and resting energy expenditure. J Pediatr 119:913-916

12. O'Rawe A, Mclntosh I, Dodge J, Brock D, Redmond A, Ward R, MacPherson A 1992 Increased energy expenditure in cystic fibrosis is associated with specific mutations. Clin Sci 82:71-76

13. Tomezsko J, Stallings V, Scanlin T 1992 Dietary intake of healthy children with cystic fibrosis compared with normal control children. Pediatrics 90:547-553

14. Cameron N 1986 The methods of auxologic anthropometry. In: Falkner F, Tanner J (eds) Human Growth, Vol 3. Plenum Press, New York, pp 3-43

15. Hamill P, Drizd T, Johnson C, Reed R, Roche A, Moore W 1979 Physical growth: National Center for Health Statistics percentiles. Am J Clin Nutr 32:607-627

16. Moore B, Durie P, Forstner G, Pencharz P 1985 The assessment of nutritional status in children. Nutr Res 5:797-799

17. Slaughter M, Lohman T, Boileau R, Horswill C, Stillman R, Van Loan M, Bemben $D 1988$ Skinfold equations for estimation of body fatness in children and youth. Hum Biol 60:709-723 
18. Schoeller D, Ravussin E, Schutz Y, Acheson K, Baertschi P, Jequier E 1986 Energy expenditure by doubly labeled water: validation in humans and proposed calculation. Am J Physiol 250:R828-R830

19. Boileau R, Lohman T, Slaughter M, Ball T, Going S, Hendrix M 1984 Hydration of the fat-free body in children during maturation. Hum Biol 56:651-666

20. Brasfield D, Hicks G. Soong S, Tiller R 1979 The chest roentgenogram in cystic fibrosis: a new scoring system. Pediatrics 63:24-3

21. Shwachman H, Kulczycki L 1958 Long-term study of one hundred five patients with cystic fibrosis. Am J Dis Child 96:6-15

22. Morris A, Kanner R, Crapo R, Gardner R 1984 Clinical Pulmonary Function Testing. 2nd ed. Intermountain Thoracic Society, Salt Lake City, pp 1-240

23. Herzog H (ed) 1987 Lung Function in Children and Adolescents-Methods, Reference Values-Progress in Respiration Research. Offsetdruck, Pratteln, Switzerland, pp 1-220

24. Braddock L, Fleisher D, Barbero G 1968 A physical chemical study of the van de Kamer method for fecal fat analysis. Gastroenterology 55:165-172

25. Silverman A, Roy C 1983 Pediatric Clinical Gastroenterology. CV Mosby, St. Louis, pp. 901-902

26. Weir J 1949 New methods for calculating metabolic rate with special reference to protein metabolism. J Physiol 109:1-9

27. FAO/WHO/UNU Expert Consultation 1985 Energy and Protein Requirements. World Health Organization, Geneva, pp $71-112$

28. Pencharz P 1985 Body composition and growth. In: Walker W, Watkins J (eds) Nutrition in Pediatrics. Little, Brown \& Co, Boston, p 79
29. Schoeller D, Leitch C. Brown C 1986 Doubly labeled water method: in vivo oxygen and hydrogen isotope fractionation. Am J Physiol 251:R1137-R 1143

30. Black A. Prentice A, Coward W 1986 Use of food quotients to predict respiratory quotients for the doubly-labelled water method of measuring energy expenditure. Hum Nutr Clin Nutr 40C:381-391

31. Murphy J, Alpert B, Christman J, Willey E 1988 Physical fitness in children: a survey method based on parental report. Am J Public Health 78:708-710

32. Bartlett M 1937 Some examples of statistical methods of research in agriculture and applied botany. J R Stat Soc B4:137-170

33. Vaisman N, Levy L, Pencharz P, Tan Y, Soldin S, Canny G, Hahn E 1987 Effect of salbutamol on resting energy expenditure in patients with cystic fibrosis. J Pediatr 111:137-139

34. Harris J, Benedict F 1919 A biometric study of basal metabolism in man. Carnegie Institution 279:1-250

35. Pencharz P, Berall G, Vaisman N, Corey M, Canny G 1988 Energy expenditure in children with cystic fibrosis. [letter] Lancet 2:513-514

36. Lucas A, Prentice A, Shepherd R 1988 Energy expenditure and cystic fibrosis. [letter] Lancet 2:737

37. Buchdahl R, Warner J 1988 Resting energy expenditure and energy intake in cystic fibrosis. [letter] Lancet 2:737-738

38. Shapiro B 1988 Mitochondrial dysfunction, energy expenditure, and cystic fibrosis. [letter] Lancet 2:289

39. Food and Nutrition Board 1989 Recommended Dietary Allowances. National Academy, Washington, DC, p 33

40. Grunow J, Azcue M, Berall G, Pencharz P 1993 Energy expenditure in cystic fibrosis during activities of daily living. J Pediatr 122:243-246 